\title{
THE GRAIN SIZE INFLUENCE ON THE E1' CENTRE OBSERVED IN QUARTZ OF ATMOSPHERIC DEPOSITION AT TWO JAPANESE CITIES: A PRELIMINARY STUDY
}

\author{
YUYA YAMAMOTO ${ }^{1}$, SHIN TOYODA ${ }^{1}$, KANA NAGASIMA $^{2}$, YASUHITO IGARASHI $^{3}$, RYUJI TADA ${ }^{4}$ \\ ${ }^{1}$ Okayama University of Science, Japan \\ ${ }^{2}$ Japan Agency for Marine-Earth Science and Technology, Japan \\ ${ }^{3}$ Metrological Research Institute, Japan \\ ${ }^{4}$ The University of Tokyo, Japan
}

Received 8 February 2010

Accepted 12 July 2010

\begin{abstract}
The grain size influence on the number of oxygen vacancies in quartz was investigated by ESR in atmospheric deposition collected at two Japanese cities, Fukuoka and Akita, in 1969 and 1971. The finer grain size fraction shows the highest value of concentration of oxygen vacancies, most closely resembling dust originating in the Taklamakan desert. Month to month and year to year variation of the dependence was also observed which could possibly be attributed to the variation of the mixture ratio of at least two dust sources in China, A conclusive statement can not be made at this stage.
\end{abstract}

Keywords: ESR, E'center, Atomospheric deposition, quartz.

\section{INTRODUCTION}

The change of atmospheric circulation system in the past is an important issue for studies of paleoclimate. Aeolian dust accumulated in the past will be a clue for such studies. In previous studies it was found that its origin was different in the last glacial maximum and in Holocene. This was achieved by measuring the number of oxygen vacancies indicated by the ESR (electron spin resonance) intensity of the $\mathrm{E}_{1}$ 'centre in quartz extracted from loess (Naruse et al, 1997; Ono et al., 1998; Toyoda and Naruse, 2002). That number in Japanese loess is 6-8 units ( 1 unit $\left.=1.3 \times 10^{15} \mathrm{spin} / \mathrm{g}\right)-$ a values similar to that found in Chinese loess plateau in MIS 1. On the other hand, for MIS 2, this is also observed in loess samples from southern Japan the values being in the range 10-17 units. These values are systematically larger in northern Japan, implying a contribution of aeolian dust from sources originating from older basement rocks. Nagashima et al. (2007) investigated the sources of the aeolian dust accumulated in the sediment of the Sea of Japan using the number of oxygen vacancies in quartz together with another proxy - crystallinity index of quartz. A correlation between the dust contribution from Taklamakan desert and the summer insolation index at $30^{\circ} \mathrm{N}$ was found.

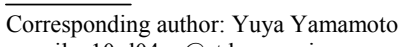

e-mail: s10rd04yy@std.ous.ac.jp

ISSN 1897-1695 (online), 1733-8387 (print) (C) 2010 GADAM Centre, Institute of Physics, Silesian University of Technology.

All rights reserved.
In the present study, we investigated the concentration of oxygen vacancies in quartz extracted from atmospheric deposition at two Japanese cities in order to examine if the same methodology with ESR is applicable to recent aeolian dust. Igarashi et al. (2009) measured radioactive isotopes ${ }^{137} \mathrm{Cs}$ and ${ }^{90} \mathrm{Sr}$ in atmospheric deposition in Japanese cities and found that the ratio $\left({ }^{137} \mathrm{Cs} /{ }^{90} \mathrm{Sr}\right)$ has been increasing with time in the last 50 years. They attributed this trend to aridification of the dust source regions within China. The ESR signals in quartz extracted from atmospheric deposition might be sensitive to such a source change.

\section{THE $E_{1}$, CENTRE AND THE OXYGEN VA- CANCY IN QUARTZ}

The $\mathrm{E}_{1}$ 'centre is a paramagnetic defect associated with an oxygen vacancy in quartz (Silsbee, 1961; Feigl et al., 1974). It is well known that its signal intensity increases during heating (e. g. Weeks and Nelson, 1960). Jani et al. (1983) attributed this phenomenon to an electronic process in which activated by heating holes at $\mathrm{Al}$ hole centres are transferred to diamagnetic oxygen vacancies with two electrons (Si-Si bond). As a result the vacancies become paramagnetic (with one electron). Using this feature, an experimental procedure was proposed to estimate the relative number of oxygen vacancies (Toyoda and Ikeya, 1991; Toyoda and Hattori, 2000). This procedure consists of a gamma ray irradiation to more 
than 200 Gy followed by heating at $300^{\circ} \mathrm{C}$ for 15 minutes. They proposed that the intensity of the $\mathrm{E}_{1}$ ' centre measured after this procedure (the heat treated $\mathrm{E}_{1}$ ' centre) corresponds to the number of oxygen vacancies in quartz.

Using this technique, a correlation between the number of oxygen vacancies in quartz and the ages of the host granites was found (Toyoda, 1992; Toyoda and Hattori, 2000). Toyoda et al. (2005) suggested that external gamma and beta rays from the minerals surrounding quartz create the oxygen vacancies.

The studies to differentiate the sources of aeolian dust using the $\mathrm{E}_{1}$ ' centre in quartz is based on the correlation between the number of the oxygen vacancies in quartz and the age of the post rocks, i.e., the method is successful when the ages of the sources of quartz, probably basement rocks, differ by an order of magnitude.

\section{EXPERIMENTAL PROCEDURE}

Dust samples representing atmospheric deposition were collected in a $4 \mathrm{~m}^{2}$ plastic open surface collector installed in the observation field of observatories at Fukuoka and Akita (Fig. 1) for one month. The collected samples in a container were heated to evaporate the water.

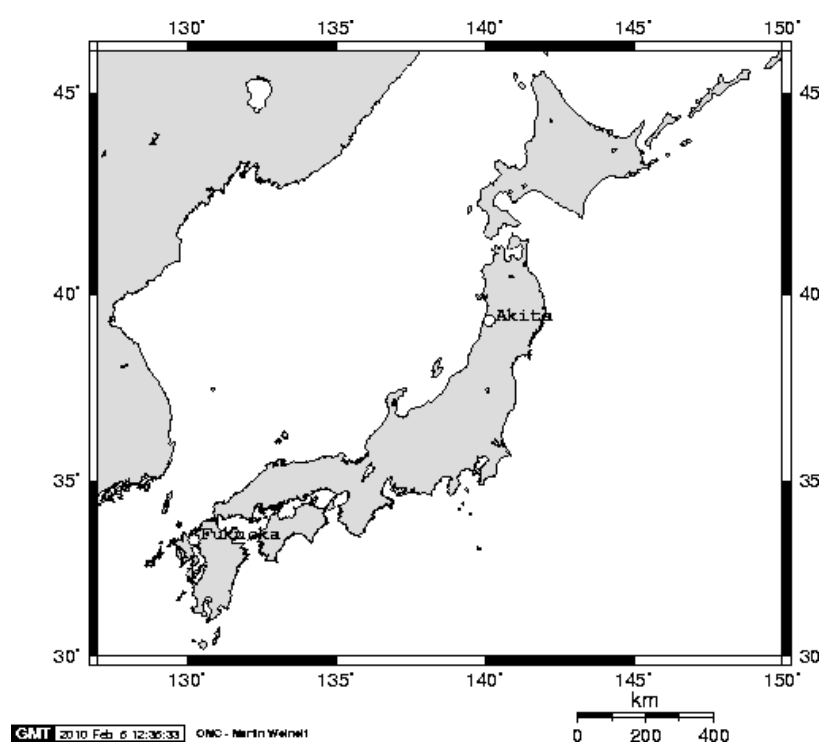

Fig. 1. The locations of the cities where atmospheric dust samples were collected.

About $150 \mathrm{mg}$ of a sample was treated with $50 \mathrm{ml}$ of acetic acid of $20 \%$ for 8 hours, then soaked in a mixed solution consisting of $40 \mathrm{ml}$ of sodium citrate $\left(\mathrm{Na}_{3} \mathrm{C}_{6} \mathrm{H}_{5} \mathrm{O}_{7}\right)$ of $0.3 \mathrm{~mol} / \mathrm{l}, 5 \mathrm{ml}$ of $\mathrm{NaHCO}_{3}$ of $1 \mathrm{~mol} / \mathrm{l}$, and $3 \mathrm{mg}$ of hydro-sulfide sodium $\left(\mathrm{Na}_{2} \mathrm{~S}_{2} \mathrm{O}_{4}\right)$ at $80^{\circ} \mathrm{C}$ for 8 hours. Subsequently, the samples were treated with $20 \%$ hydrogen peroxide solution $\left(\mathrm{H}_{2} \mathrm{O}_{2}\right)$ and heated at $60^{\circ} \mathrm{C}$ for 8 hours. The sample was then separated to grain size fractions, $>32 \mu \mathrm{m}, 16-32 \mu \mathrm{m}, 8-16 \mu \mathrm{m}$, and $4-8 \mu \mathrm{m}$ with the application of the Stoke's law.

ESR signals in the samples were measured with an ESR spectrometer, JEOL JES-PX2300. The number of oxygen vacancies was measured as the intensity of the $\mathrm{E}_{1}$ ' centre after gamma ray irradiation to $1 \mathrm{~Gy}$ and heating at $300^{\circ} \mathrm{C}$ for $15 \mathrm{~min}$ (Toyoda and Ikeya, 1991). The following measurement conditions of the ESR were used: the microwave power of $0.01 \mathrm{~mW}$, the magnetic field modulation frequency of $100 \mathrm{kHz}$, its amplitude of $0.1 \mathrm{mT}$, the centre field of $336.0 \mathrm{mT}$, the sweep range of $5 \mathrm{mT}$. The measurements were carried out at room temperature.

\section{RESULTS}

The number of oxygen vacancies measured in quartz of our dust samples are shown in Figs. 2a for Fukuoka and $\mathbf{2 b}$ for Akita as a function of grain size. The numbers of the oxygen vacancies are described in a unit of $1.3 \times 10^{15} \mathrm{spins} / \mathrm{g}$ as was done in previous studies (Toyoda and Naruse, 2002; Nagashima et al., 2007). It is a common feature that smaller grain size fractions show higher number of oxygen vacancies although there are month to month and year to year variations in the average level. The ESR signal of the $\mathrm{E}_{1}$ 'centre was not detected due to a large interfering signal in all samples in February 1969 at Fukuoka. The values are higher for 1969 than for 1971 at both cities. The average level is higher in April than in February at Akita but the opposite is true for Fukuoka in 1971.

A reason for the higher number of oxygen vacancies in finer fractions may be that the signal is related to a surface defect. However, this is not the case as the number is not inversely proportional to the grain size.

\section{DISCUSSION}

Kosa is a very well-known meteorological phenomenon of aeolian dust storm generated in inland China arriving in Japan. The sky is so hazy that one can see the precipitating dust. The location-days totals are listed in Table 1 , which is the sum, for the observatories, of the number of days in a month, on which Kosa was observed. The number is larger in 1969 than in 1971, being consistent with our results that the numbers of oxygen vacancies in quartz are larger in 1969 than in 1971. This would indicate that the main part of the precipitated atmospheric dust was brought by Kosa, having higher oxygen vacancy values from inland China. The number of oxygen vacancies in finer fraction, ranging up to 8.5 units is consistent with the values observed by Toyoda and Naruse (2002), for MIS 1 or in southern Japan and in inland China for MIS 2, which is 6-8 units, and that of Taklamakan component reported by Nagashima et al. (2007), which is 8.8 units. This is also confirmed by our observation of the local river sediments in the present study. The numbers of oxygen vacancies in quartz from river sediments which are possible local dust components, were 1.23 units in Fukuoka and 1.75 units in Akita, indicating that those high values are not local. Figs. 3a and $\mathbf{3 b}$ shows the fraction of the mass of the grain sizes of the total mass of quartz extracted. 


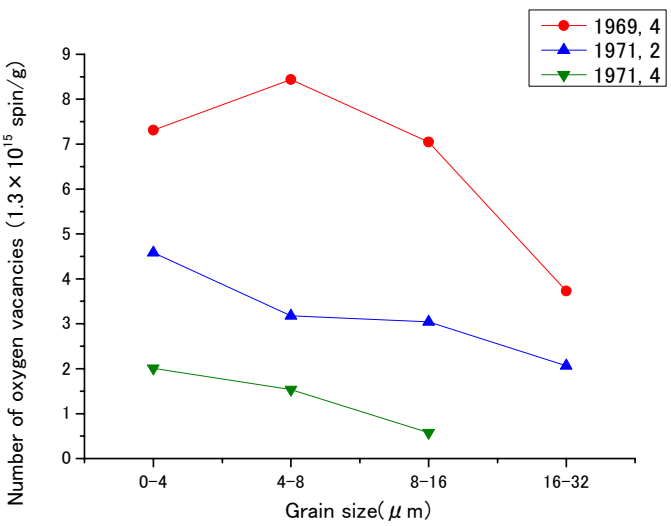

A

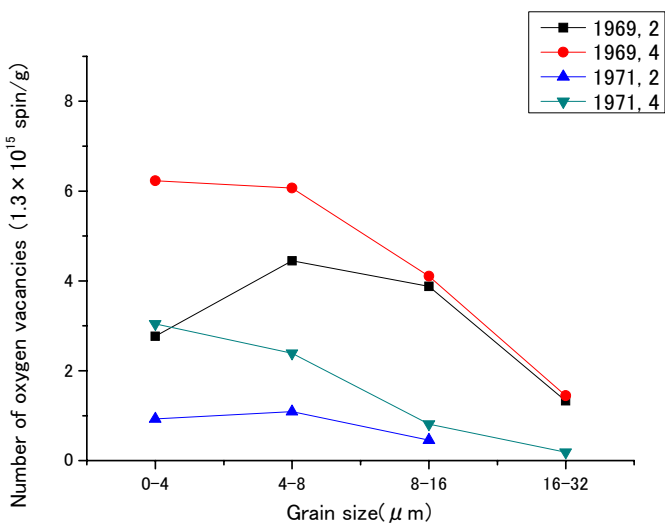

B

Fig. 2. Grain size distributions of oxygen vacancies in quartz of atmospheric deposition collected (A) at Fukuoka and (B) at Akita

All samples show bimodal distribution. It is natural to interpret these two components as aeolian dust peaking at less than 4 micrometers and the coarser local sediment, although the amount in coarser fractions is larger in $\mathrm{Fu}-$ kuoka. This indicates that we should look at grain size fractions less than $8-16 \mu \mathrm{m}$ to examine aeolian dust in atmospheric deposition. If the fine component corresponds to the aeolian dust from China and coarser component to local, our results on the highest values shown in Figs. $\mathbf{2 a}$ and $\mathbf{2 b}$ are consistent with the discussions in the previous paragraph. The number of oxygen vacancies in the finest two fractions would represent the values for dust coming from China, while the values for coarser fractions are lower because of the mixture of local quartz with lower oxygen vacancy values.

However, the results for the other finer fractions shown in Figs. 2a and $\mathbf{2 b}$ are not so simple. The numbers of oxygen vacancies in finer two fractions for April 1969 are 6.0-8.5 units both at Fukuoka and Akita, being consistent with the values for Taklamakan (Nagashima et al., 2007) while the values are lower in 1971 at both cities and in Feb. 1969 at Akita. We could still adhere to the idea that finer fractions are aeolian dust from China, to explain these lower values. It would be supported by the grain size distribution shown in Figs. 3a and $\mathbf{3 b}$; the grain size distributions are not much different except for April 1971 at Fukuoka where the fraction for the smallest grain

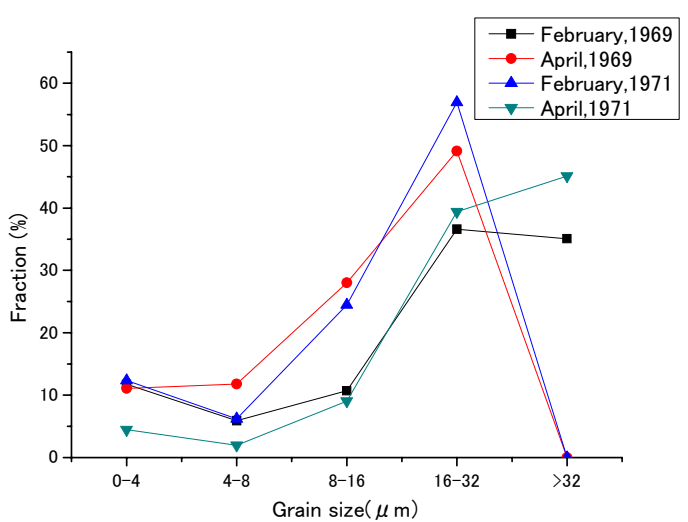

A

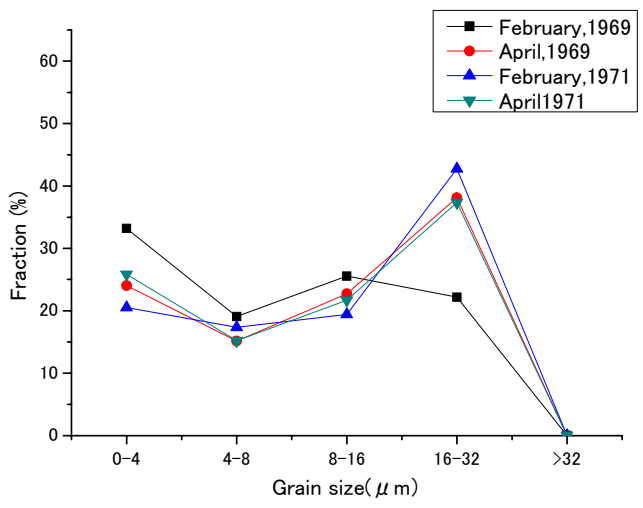

B

Fig. 3. Grain size dependence of fractions of mass of quartz extracted for the sample (A) at Fukuoka and (B) at Akita

size is less than $5 \%$. There is no clear correlation between the oxygen vacancy values and the mass of the atmospheric deposition (Table 1), neither. These facts would imply that the number of the oxygen vacancies in dust from China varies from one month to another month and from one year to another year. One could explain this by the dust originating from at least two sources, where one may be the Taklamakan desert and the other should have a lower oxygen vacancy value, and depending on the ratio of the mixture, the oxygen vacancy values vary between months and years. Akita would more clearly show this feature. In February, the dust starts in the second source with a lower oxygen vacancy values, then the first source with higher value, maybe Taklamakan, dominates in April, but the contribution from the second source would have been generally larger in 1971 .

However, it is still possible that local dust has contributed to finer fractions, making the oxygen vacancy values lower. As the present study is a preliminary work to examine the oxygen vacancies in atmospheric deposi tion, and examines only one parameter, it is not possible to discuss more than two components. Further studies are necessary to examine other features of quartz, such as crystallinity index, oxygen isotopes, ESR intensities of impurity centres. 
THE GRAIN SIZE DEPENDENCE OF THE E1'CENTRE E1'CENTRE OBSERVED IN QUARTZ ...

Table 1. The mass of the collected atmospheric deposition and the number the days on which Kosa was observed.

\begin{tabular}{|c|c|c|c|c|}
\hline Year & Month & $\begin{array}{c}\text { Mass of the collected } \\
\text { atmospheric deposition (g) } \\
\text { at Akita }\end{array}$ & $\begin{array}{c}\text { Mass of the collected } \\
\text { atmospheric deposition (g) } \\
\text { at Fukuoka }\end{array}$ & Location-days total* \\
\hline 1969 & February & 7.93 & 10.67 & 0 \\
\hline 1969 & April & 14.35 & 24.08 & 276 \\
\hline 1971 & February & 10.44 & 13.28 & 2 \\
\hline 1971 & April & 18.85 & 17.25 & 43 \\
\hline
\end{tabular}

\section{SUMMARY}

The numbers of oxygen vacancies in quartz of atmospheric depositions were investigated. Finer fractions show higher values where the highest values are consistent with the dust value at Takalamakan desert, while the coarser fraction indicates the local values as is also indicated from the grain size distribution. The grain size distribution indicates that the size fractions less than 8$16 \mu \mathrm{m}$ should be examined to study the aeolian dust component. The pattern of the oxygen vacancy values versus grain size varies month to month, year to year. No conclusive explanation was obtained in the present study while it is possibly because of variations of mixture ratio of two or more dust sources in China.

\section{ACKNOWLEDGEMENTS}

This study was financially supported by Grant-in-Aid for Scientific Research awarded to Shin Toyoda, 20651005

\section{REFERENCES}

Feigl FJ, Fowler WB and Yip KL, 1974. Oxygen vacancy model for the $\mathrm{E}_{1}{ }^{\prime}$ centre in $\mathrm{SiO}_{2}$. Solid State Communications 14: 225-229. DOI 10.1016/0038-1098(74)90840-0

Jani MG, Bossoli RB and Halliburton LE, 1983. Further characterization of the $E_{1}{ }^{\prime}$ centre in crystalline $\mathrm{SiO}_{2}$. Physical Review $B$ 27: 2285-2293. DOI 10.1103/PhysRevB.27.2285

Nagashima K, Tada R, Tani A, Toyoda S, Sun Y and Isozaki Y, 2007. Contribution of aeolian dust in Japan Sea sediments estimated from ESR signal intensity and crystallinity of quartz. Geochemi- stry Geophysics Geosystems 8 (2): Q02Q04, DOI 10, 1029/2006GC001364.

Naruse T, Ono Y, Hirakawa K, Okashita M and Ikeya M, 1997. Source areas of eolian dust quartz in East Asia: a tentative reconstruction of prevailing winds in isotope stage 2 using electron spin resonance. Geographical Review of Japan. 70A-1: 15-27 (in Japanese).

Igarashi Y, Inomata Y, Aoyama M, Hirose K, Takahashi H, Shinoda Y, Sugimoto N, Shimizu A and Chiba M, 2009. Possible change in Asia dust source suggested by atmospheric anthropogenic radionuclides during the 2000s. Atmospheric Environment 43: 2971-2980. DOI 10.1016/j.atmosenv.2009.02.018.

Ono Y, Naruse T, Ikeya M, Konho H and Toyoda S, 1998. Origin and derived courses of eolian dust quartz deposited during marine isotope stage 2 in East Asia, suggested by ESR signal intensity. Global and Planetary Change 18(3-4): 129-135. DOI 10.1016/S0921-8181(98)00012-5.

Silsbee RH, 1961. Electron Spin Resonance in Neutron-Irradiated Quartz. Journal of Applied Physics 32: 1459-1462. DOI 10.1063/1.1728379.

Toyoda S, 1992. Production and decay characteristics of Paramagnetic defects in quartz: application to ESR dating. Ph.D. Thesis, Osaka University, Japan, 106p.

Toyoda S and Hattori W, 2000. Formation and decay of the $\mathrm{E}_{1}$ ' centre and of its precursor. Applied Radiation and Isotopes 47: 13511356. DOI 10.1016/S0969-8043(00)00094-4.

Toyoda S and Ikeya M, 1991. Thermal stabilities of paramagnetic defect and impurity centres in quartz: Basis for the ESR dating of thermal history. Geochemical Journal 25(6): 437-445.

Toyoda S and Naruse T, 2002. Eolian dust from the Asian deserts to Japanese Islands since the lost Glacial Maximum; the basis for the ESR method. Transactions, Japanese Geomorphological Union 23: 811-820.

Toyoda S, Takeuchi D, Asai T, Komuro K and Horikawa Y, 2005. Spin-spin relaxation time of $\mathrm{E}_{1}$ 'centre in quartz with and without irradiation: implications for the formation process of the oxygen vacancies in nature. Radiation Measurements 39: 503-508. DOI 10.1016/j.radmeas.2004.09.002.

Weeks R A and Nelson C N, 1960. Trapped electrons in irradiated quartz and silica. II. Electron Paramagnetic Resonance. Journal of the American Ceramic Society 43: 399-404. DOI 10.1111/j.11512916.1960.tb13682. 